\title{
'Fast-track' drug approvals hit speed bumps in Japan
}

Families of patients who died after receiving the controversial cancer drug Iressa (gefitinib) in July filed a lawsuit against manufacturer AstraZeneca and the Japanese government for $¥ 33$ million, alleging that the drug, approved in Japan in 2002 after only five months of review, showed neither adequate safety nor efficacy in clinical trials. The case highlights increasing concern about Japan's growing tendency to speed up drug approvals.

Iressa is known to cause interstitial lung disease (ILD) in some patients. Six months after its release, 124 Iressa-related deaths had been reported, prompting Japan's Ministry of Health, Labor and Welfare to issue stricter prescription and informed consent parameters for the drug. But by the end of March 2004, the ministry had tallied 444 deaths and 1,151 cases of the disease.

Rokuro Hama, who heads the Japan Institute for Pharmacovigilance, has been a vocal critic of the scientific basis for Iressa's approval in Japan. "The classification of adverse effects in both the toxicology and the clinical trials was arbitrary and poorly designed, and the post-marketing studies showed no survival advantage," Hama says. "Iressa should never have been approved."

In 2003, Hama filed his own suit against the Japanese government, petitioning for release of the full results of animal toxicity tests, which he says might reveal flaws or inconsistencies in preclinical studies of the drug.

AstraZeneca has denied legal responsibility for the deaths, saying it complied fully with government regulations in marketing the drug in Japan. Iressa has been approved in 20 countries without similar reports of adverse events, notes Tomoko Haruna, a spokesperson for the company. "Obviously, there can be side effects with any drug."

Akira Inoue, who published one of the earliest case studies of Iressa-related deaths, says that given the high mortality rate among people with lung cancer, Iressa's risk-benefit profile is acceptable. But it's important to identify individual risk factors, such as possible genetic differences in patients who experience adverse reactions, says Inoue, a researcher at Tohoku University.

Scrutiny of the case in Japan has focused in part on the speed of Iressa's approval, the fastest on record for a non-AIDS-related drug.

'Fast-track' approvals began in Japan in 1993 to hasten the approval of AIDS drugs. The priority review was meant to speed up some administrative aspects, without compromising rigorous standards for safety and efficacy, says
Yoshikazu Hayashi, a deputy director in the ministry's Pharmaceutical and Food Safety Bureau. Priority approvals have since become common and the trend seems certain to continue, if not accelerate. In April, the government streamlined the regulatory system and fused three centers into the new Pharmaceuticals and Medical Devices Agency, which aims to shorten the review process to six months or less for at least half of all fast-tracked applications. The ministry has also instituted a 'time clock' system, calling for review times to be reduced to an average of 12 months.

Industry players are naturally pleased with the loosening of Japan's famously tight restrictions, a move intended to make the country an easier place to do business. But patient advocacy groups and industry watchdogs have criticized the way the new policies have been put into practice. Of primary concern is the increasing reliance on post-marketing tests, which depend heavily on self-reporting by drug makers, as a safety measure for fast-tracked pharmaceuticals.

In June, Aventis, which makes the antirheumatic agent Arava (leflunomide), found that during post-marketing monitoring of 3,658 Japanese patients who had received the drug, 11 patients died and 29 developed ILD. Reports of ILD incidence for both Iressa and Arava have been significantly higher in Japan than in other parts of the world.

"The two drugs are quite different in terms of their chemistry and modes of action," notes Yoshiji Fujita, who last year headed a project at the Tokyo Medical University Clinical Proteome Center to identify factors associated with adverse reactions to Iressa. "We can't rule out that there may be an ethnic component to ILD susceptibility."

Douglas Sipp, Kobe

\section{UK cracks down on animal-rights activists}

Animal-rights activists were dealt a dual blow in late July when the UK government and the pharmaceutical industry announced new legislation and funds to support animal research.

Activists seemed to have scored another victory when the building contractor Montpellier on 19 July withdrew from plans to build an $\mathfrak{E} 18$ million animal research center at Oxford University, after its shareholders received threatening letters. The University of

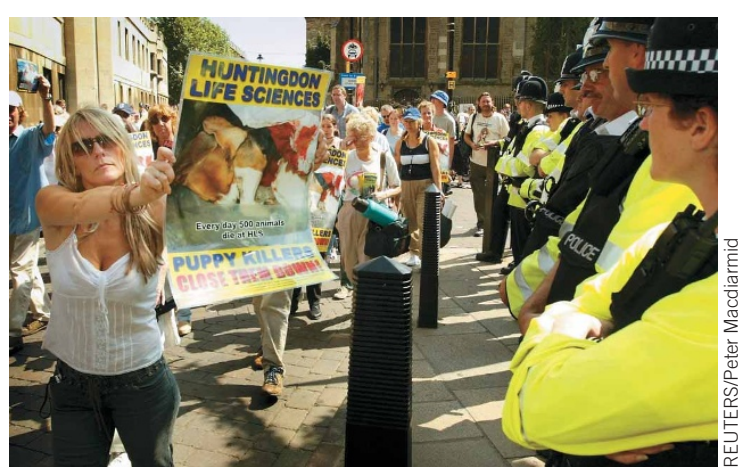

New laws make life difficult for protesters, who have prevented the launch of at least two research centers in the UK. plan for a new primate research center after a similar campaign (Nat. Med. 10, 215; 2004).

But on 30 July, the UK government made protesting outside an individual's home an arrestable offense, and warned that animal-rights extremists are "organised in a quasi-terrorist cellular structure." Under the new policy, harassment laws will be extended to cover groups of employees, and a specialist police unit and 43 specialist prosecutors will tackle violent protestors.

The new report is "clearly the strongest statement yet of the government on the issue and leaves no doubt at all that they intend to resolve the problem," says Mark Matfield, executive director of the Research Defence Society, which represents scientists engaged in animal research.
On the same day, drug giants GlaxoSmithKline, AstraZeneca and Pfizer also launched a four-year $\mathfrak{E} 4$ million research fund to pay for animal experiments. The companies said they would back fellowships and pay for lab equipment to help universities continue animal testing.

Supporters of animal research welcomed the developments, but some caution that activists will not so easily be thwarted. "Identification of the seriousness of the problem is a step forward, [but] I doubt if it will inhibit the more determined political activists," says Ian Gibson, chair of the House of Commons Science and Technology Committee.

Xavier Bosch, Barcelona 